\title{
'It used to be brutal, now it's an art': changing negotiations of violence and masculinity in British karate
}

Chloe MacLean

MacLean, C. (2019). 'It used to be brutal, now it's an art': changing negotiations of violence and masculinity in British karate. In: Handbook of Masculinity and Sport.

Reproduced with permission of Palgrave Macmillan.

This extract is taken from the author's original manuscript and has not been edited. The definitive, published, version of record is available here: URL for the product on www.palgrave.com and www.link.springer.com 
Running head: NEGOTIATIONS OF VIOLENCE \& MASCULINITY IN BRITISH

KARATE

'It used to be brutal, now it's an art': Changing negotiations of violence and masculinity in

British karate.

Chloe Maclean

Abertay University, Dundee 


\begin{abstract}
In most western (and indeed eastern) cultures, fighting is seen as an ultimate symbol of masculinity - an embodied display of dominance, control and violence (Bourdieu, 2001). As a space legitimizing and praising performances of mimetic violence (Dunning, 1999), combat sports provide an arena where the virtues of dominance and power at the heart of conceptions of orthodox masculinity (Anderson, 2005) or hegemonic masculinity (Connell, 2005) can be symbolically presented by men through bodily displays of strength, physical aggression, and the taking and overcoming of pain (Bourdieu, 2001; Messner, 1990; Wacquant, 2004). Yet, over the last 20 years the focus of karate in Britain has been perceived to shift from aggressive acts of 'hitting hard' to developing and displaying controlled, acrobatic and technically precise movements. Drawn from a nine-month ethnography and seven semi-structured interviews, this chapter explores how British male karate practitioners re/negotiate ideas of masculinity and embodiments of a masculine identity in the context of karate's changing emphasis on, and practices of, 'violence.'
\end{abstract}

This paper suggests that a 'civilizing' shift (Elias \& Dunning, 1986) in the competition rules and increases in women's participation in karate complicate the use of violence as a symbol of praised masculine identity within British karate. A praised masculine identity is crafted by carefully blending traits conventional deemed feminine such as technical precision, elegance and agility alongside displays of strength and dominance. Such performances challenge conceptions of an orthodox sporting masculinity and notions of hierarchical gender distinction. 


\section{'It used to be brutal, now it's an art': Changing negotiations of violence and masculinity in British karate}

At the heart of constructing sport as a male domain has been the positioning of sport as an arena to perform mimetic physical violence (Dunning, 1999), and of such violence as central to, and a reflection of, masculine identity and men's superiority over women (Connell, 1990; 2005; Messner, 1990). Fighting in particular has been historically represented as an exercise of power expected of men and imagined to be innate to men (Bourdieu, 2001; Hatty, 2000). As such, combat sports, on the face of it, present arenas where the virtues of dominance and power. These virtues are at the heart of conceptions of hegemonic masculinity - a dominant form of masculinity constructed in hierarchical comparison to femininity and subordinated masculinities (Connell, 2005); and orthodox masculinity - a conservative form of masculinity that, whilst not necessarily hegemonic in a given field, is centered around compulsory sexism, homophobia, and stoic bravado (Anderson, 2009). Within contact and combat sports, dominance and power can be symbolically presented by men through bodily displays of strength, physical aggression, and the taking and overcoming of pain (Bourdieu, 2001; Messner, 1990; Wacquant, 2004).

Karate is a martial art and sport centered on the development of combative and defensive techniques such as kicks, punches, strikes and throws. Its practice involves both individual and partnered practice to improve the precision of such techniques. Despite the association often made between combat sports, violence, and orthodox masculinity, over the last thirty years the focus of karate in Britain has been perceived to shift from aggressive acts of 'hitting hard' to developing and displaying controlled, acrobatic and technically precise movements. In line with this shift, British karate has seen steady increases in female participation, whereby women can, 
and often do, outperform men at what is deemed to be an innate capacity for combative violence (Maclean, 2015). As such, this paper seeks to explore how British male karate practitioners re/negotiate ideas of masculinity and embodiments of a masculine identity within the context of karate's changing emphasis on, and practices of, 'violence'.

\section{Sports Violence}

Tied into the virtues of the enlightenment era, Elias suggests society went through a 'civilizing process' (Elias, 1994) whereby bodily impulses and emotions were viewed as oppositional, and subordinate to, rationality. Within this civilizing shift, the use of violence as an act of physical punishment upon the body was reconceptualized as acts which lacked refinement, morality, rationality, and thus civility. Dunning (1999) suggests the rendering of violence as taboo in everyday life as a product of the civilizing process cut into a source of power

predominantly monopolized by men, and a key source of their power over women. As society became less violent, and women gained greater access into public life, modern sport became central to men's societal life through its functions of providing excitement within an increasingly passive everyday life (Elias \& Dunning, 1986), and as a means of mimetically maintaining the association between men, violence, and the power associated with violence (Dunning, 1999).

The apparent violence of sport, however, brings both excitement and moral uncertainty. Sports such as American football, boxing, rugby, ice hockey and combat sports face on going challenges to their structure and practice due to concerns over the physical damage participants tacitly inflict upon one another as part of the sports practice. Indeed, sports play is enshrined with what appears to be ritual and interpersonal violences that are central to play (Pringle, 2009; Young, 2012). 
Within this context, athletes are positioned within on-going negotiations of aggressive physical contact that may or may not be interpreted by the athletes themselves as violent, and the meaning of violence becomes complicated. Matthews and Channon (2017) suggest that for sports actions to qualify as violence rather than sporting mimetic expressions, they should meet two criteria: violence as intended force against another, and violence as violation. Athletes often look toward sports rules as providing the boundaries for what is forceful but instrumental, and forceful acts that are violations (Garcia \& Malcolm, 2010; Messner, 1990; Wacquant, 2004). The rules combine with athletes' own tacitly negotiated agreements of physicality level, whereby what may appear to a spectator as violent acts, are not experienced by participants as violation:

What has every chance of looking like a spree of gratuitous and unchecked brutality in the eyes of a neophyte is in fact a regular and finely codified tapestry of exchanges that, though they are violent, are nonetheless constantly controlled, and whose weaving together supposes a practical and continual collaboration between the two opponents in the construction and maintenance of a dynamic conflictual equilibrium (Wacquant, 2004, p. 85).

Central to the construction of 'conflictual equilibriums' is emotion management (Hochschild, 1983), trust (Spencer, 2012) and emotional reflexivity of others involved in the sports practice (Smith, 2014). Higher and lower parameters of enjoyment reflective to the levels of mimetic violence unfold, whereby breaking the upper limit crosses trust levels and causes injury, and breaking the lower removes excitement (Garcia \& Malcolm, 2010). Actions that sit ambiguously as instrumental sporting uses of physical aggression - such as a late tackle and hard 
hits - stretch the use of players' consent alongside adding excitement. As such, violence in sport is a complicated embodied negotiation of interpersonal and ritual violences reliant on emotional reading and management that can fall between being mimetic and being experienced as a violation.

\section{Sports violence and masculinity}

As a space legitimizing and praising performances of mimetic violence, sport provides an arena where the virtues of dominance and power at the source of gender difference (Kimmel, 2000) can be symbolically presented by men through bodily displays of strength, the taking and overcoming of pain, and displaying and exerting physical aggression whereby "sporting prowess becomes a test of masculinity" (Wellard, 2001, p. 239) and men's bodies 'become weapons' (Messner, 1990). Differing sports are afforded different levels of association with masculinity reflective to ever-changing cultural frameworks, whereby sports involving heavy interpersonal contact, and embody the values of an orthodox masculinity, are commonly granted a particular prestige. In such sports, in order to win and show one's superiority over an opponent, men learn to use their bodies in ways that exude physical force upon opponents; receive and disregard physical harm; take risks; and command space/ defend territory (Kidd, 2013; Messner, 1992;

Schacht, 1996; Smith, 2014; Spencer, 2012). Through such tacit interactions men's participation in sport conditions their bodies in ways that enables physical dominance and power to appear as 'natural' capacities. The naturalization of aggression to men and their bodies underpins a rhetoric expressed by athletes, publics, and academics alike, that the 'violence' of contact sports funnels an 'innate' energy that prevent men, particularly working class and black men, from engaging in criminal violence (Wacquant, 2004). 
The value denoted to physically dominating, aggressive, uses of men's bodies is suggested to be produced and maintained through opposition to conceptions of femininity as weak and fragile (Anderson, 2008; Curry, 1991; Kidd, 2013; Klein, 1993; Schacht, 1996). The exclusion or subordination of women in sport further enables the association between violence, dominance, power, and masculinity to appear as a legitimate reflection of men and women's different natures, and in turn, their different power positions in the world (Anderson, 2008; Hatty, 2000; Hargreaves, 1994; McDonagh \& Pappano, 2008). Distinction from women and femininity has thus been implicitly or explicitly made central to many men's sporting embodiment, whereby mimetic displays of violence have been a key component of expressing such difference.

Yet, the physical demands of passing the test of masculinity can do short and long-term damage to men's bodies. In such moments, men's bodies are made fragile, and masculine identity brought into contention, through the very mechanism that promises masculine prestige (Laurendeua, 2014). In turn, men are often encouraged to hide feelings of pain and anxieties related to pain by replacing these displays with 'appropriate' masculine responses such as continuing to play or complimenting the opponents attack on their body, in order to maintain a presentation of sporting capability, and of orthodox masculinity (Laurendeua, 2014; Spencer, 2012). Such research suggests that the practice of sport does not simply recreate an orthodox masculine embodiment, but rather, is an arena overburdened by hegemonic ideas of men and masculinity, actively engaged with by men in ways that construct or reject such notions to varying degrees.

\section{Combat sports and masculinity}


Within the context of a civilizing society, martial arts and combat sports (MACS, hereafter) have been cited as practices where men can explicitly mirror the violence of fighting in a controlled and regulated setting. Men's participation in MACS thus retains virtues of physical aggressive domination as a visual and embodied expression of their masculinity in a manner deemed legitimate, (broadly) socially praised, and distant from 'real' violence (Garcia \& Malcolm, 2010; Spencer, 2012; Smith, 2014; Sugden, 1996; Wacquant, 2004; Woodward, 2006). For many men, the association between violence and masculinity is central to the enjoyment of MACS (Garcia \& Malcolm, 2010; Spencer, 2012; Woodward, 2006).

Whilst such literature often emphasizes ways in which orthodox masculinity is performed, much of the processes of combative practice involve trust, control, and care for training partners (Maclean, 2016; Smith, 2014). Channon (2013) further suggests that some male martial artists choose to learn a martial art rather than western combat or contact sports precisely to distance themselves from sporting masculinities that were perceived to valorize violent, dominating and confrontational embodiments. Such research suggests that MACS can develop men's gendered embodiment in opposition to orthodox masculine values such as dominance and violence.

The tendency for MACS to have sex-integrated, mimetically violent, practice presents particular challenges to constructions of an orthodox masculinity. A central argument made by many MACS scholars exploring gender is that the increasing commonality of women's participation disrupts men's monopoly of fighting skills, and as such, the power, prestige, and grounds for gender distinction drawn from and attached to fighting ability (Channon, 2013; Channon \& Matthews, 2015; MacLean, 2015; McNaughton, 2012; Noel, 2009). Thus, women's increasing participation in MACS draws the societal links between men, fighting, and 
domination into question, and in turn blurs the masculinity-validating qualities of MACS. Much of this literature has focused on women's constructions of gender (for examples see: Channon \& Matthews, 2015; MacLean, 2015; McNaughton, 2012; Mennesson, 2000; Noel, 2009). The prominent academic omission of gendered analysis of men's participation in MACS both reinforces both a dualistic positioning of men as the norm and women as 'other', and ideas of women and men as having distinct natural competencies that thus do not warrant exploration. Men's capacity for, and interest in, violence often emerges as one of the overlooked and naturalized elements of men's participation in MACS.

Attending to this omission, this paper seeks to explore how male karate practitioners in Britain experience and applying meaning to mimetic, and sometimes purposeful, acts of physical violence within mixed sex karate training. In turn, the link, or disruption, between orthodox masculinity, dominance, and violence will be explored in order to explore how men construct a sense of masculinity and masculine embodiment within karate practice. This paper suggests a praised masculine identity is crafted by carefully blending traits conventional deemed feminine such as technical precision, elegance and agility, alongside displays of strength and dominance. Such performances challenge conceptions of an orthodox sporting masculinity and notions of hierarchical gender distinction.

\section{Methodology}

In order to explore how men negotiated violence and masculine embodiment within the changing context of British karate, a sensory ethnographic research design was adopted. This approach sought to illuminate the lived, carnal experiences of men's bodies within karate practice that inform their embodiment and, through processes of reflection, in turn informed their 
sense of gender identity (Pink, 2009). Sport has been broadly recognized as a heightened arena oozing bodily sensations between bodies within play, whereby participants draw upon space, movements, sounds, textures, tacit exchanges, pain, balance, sensations of heat from the body, and smells to inform play and provide the building blocks for participants sense of embodiment (Allen-Collinson, 2009; Raven \& Hansen, 2013; Spencer, 2013). A sensory ethnography was thus particularly well suited to this project as the mimetic violence of karate is indeed expressed through, and felt upon, the body, whereby the meanings applied to 'violent' combative actions and their relationship with notions of orthodox masculinity, are done so in relation to sensory embodied experience.

The research was conducted across three British karate clubs, and consisted of a combination of participant-observations and photo-elicitation interviews. The karate clubs were given the pseudonyms Lothian Wadokai, Juniper Karate Club and Bushido. Both Lothian Wadokai and Juniper Karate Club were located in Scotland, and Bushido in the North East of England. In researching multiple karate clubs, the difference and similarities between clubs could be illuminated, and as such variances in the karate club context surrounding men's negotiations of masculinity and violence could be identified. An adults' karate class at each club was attended at least once per week across a period of nine months, and observations of gendered negotiations of combative tacit exchanges, performances of gender, and gendered interactions were recorded after each class.

Seven one-to-one photo-elicitation interviews with men from across the three karate clubs followed from the participant observation, and aimed to supplement the observational data by providing insights into men's embodied experiences within karate practice, and in turn illuminate how they negotiated and applied meaning to combative 'violence' within karate. The 
participants ranged from 22 to 50-years-old; many of the latter had trained in karate for over 20 years. This enabled comparisons of ideas of violence to constructions of masculinity within karate across time. As the topic of gendered embodiment/identity and moral negotiation of what is deemed violent is indeed very personal, an approach was required that allowed participants to feel comfortable and open to discuss their experiences. Photo-elicitation interviews offered opportunities to give the interviewees some control over the direction of the interview (Meo, 2010; Wang, 1999), which was hoped to ease tensions and anxieties of discussing gender with a female researcher (Padfeild \& Procter, 1996; Pini, 2005). Participants were asked to bring photographs demonstrating 'the good, the bad, and the ugly' of karate to the interviews. The photographs were used to enable the meanings men applied to 'violence' within karate to emerge from the 'bottom-up'. The photographs also provided reference points from which the researcher could steer the conversation towards discussions of violence and gender relations, whilst still enabling the participants to both have a visual reference to inform their discussions and a familiarity with the topic (Meo, 2010) which in turn eased discussion.

Interview transcripts, photographs, and field notes were then thematically coded for violence, and then coded again to identify sub themes. Drawn from the myriad of data gathered on violence, this article draws on three phenomena affecting the relationship between ideas of violence and embodiments of masculinity within the everyday practice of karate in Britain: a civilizing process in karate's competition rules; the coinciding shift of prestige to actions that display elegant, artistic, control; and the policing and punishing of violence within the karate hall.

\section{Feeling rules and emotion management}


The class broke out into pairs across the hall to practice partnered work. The practitioners were asked to perform a set sequence of moves that had both attacking and defensive elements. Eric, a man in his mid 40s whom had been doing karate for around 18 months, was paired with Angela - a woman of similar age but with much more experience. Eric's body exuded an anxiety with the attacking elements of the partnered work. His body was tense, shoulders high, eyes wide with raised eyebrows and movements both rigid and short of making contact with Angela's body. There was no flow to his movements, no sharp and snappy speed, no determination, and a distinct lack of intention and aggression. At a distance coach Katie watched the pair as they practiced their partnered work backwards and forwards. 'You didn't mean that. Did you mean that punch? Because if you did, then why was it short? You need to look like you mean it! There should be fire in these techniques!' Katie's face was animated as she confronted Eric, almost illustrating the expressions she was seeking in Eric's techniques. To demonstrate her point, Katie performed a swift punch that threw dynamic energy right through her body honed into her fist to Angela's body. Katie's eyes were pierced upon Angela's body, her mouth tightened, eyebrows sharp, and simultaneously as her fist landed on Angela's body Katie gave an aggressive shout 'Kiai!' Resuming to a standing position, Katie explained 'See, that's what we need from you'.

Fieldnotes, Bushido.

The mimetic violence of karate involves a performance of combative moves, but also embedded within each kick, punch, throw, or strike, is a set of expected embodied emotional expressions. The execution of a punch involves simultaneously the twisting of the hips, 
tightening of the fists, lowering of the eyebrow, a sharp focus within the eyes, extension of the arm, and a shout of aggression as the fist lands upon the opponent's body that together, mark the technique as successful, and work to express the karate athlete's dominance over their opponent. The tightening of the skin around the eyes and jaw work to perform a determination and aggression that is expected of karate practitioners, that suggests a fearless readiness for violence. An expectation to express fearlessness and willingness for aggression marks a primary feeling rule (Hochschild, 1983) of karate. As the vignette above suggests, karate practitioners were held tightly to obeying this feeling rule through informal disciplining from their instructors.

Alongside maintaining an expression of a determined, fearless, readiness for performing mimetic violence, there appeared to be four other key feeling rules that frame expressions and experiences of violence within contemporary British karate classes. Together, the five feeling rules were:

1. Practitioners must maintain an expression of determined, fearless, readiness for executing mimetic violence during their practice.

2. Practitioners must hit their training partners or competition opponents, however, with a degree of control.

3. Practitioners must not feign injury, or express pain when hit.

4. Practitioners should accept being hit, or being defeated in competition, with humble respect for their partner/opponent.

5. Practitioners should not hold an intention to hurt those they train with or compete against.

These exist as informal feeling rules informing karate practice. Whilst they are not explicitly listed prior to karate classes, or written down within the license books karate 
practitioners keep, practitioners learn these rules through club instructors or those in senior positions within karate clubs such as black belts explicitly informing practitioners to alter their practice in accordance with these feeling rules; through a variety of tacit exchanges that encourage increased or decreased physicality of a karate practitioners practice; and watching those in senior positions within the club.

The extent to which these five feeling rules are maintained during karate practice has multiple complexities and variances, that in turn reflect the difficulty in creating a clearly defined line of what violence is mimetic or real (Young, 2012). A key pattern that emerged within the karate clubs explored was that men were often held much tighter than women to all five feeling rules than women. The five feeling rules guiding experiences and expressions of violence within karate as outlined here are intertwined within and further illuminated in the analysis of masculinity in the following findings sections. With violent capacity theorized to be a key component of an orthodox masculinity (Anderson, 2005; Bourdieu, 2001) the following sections focus on how karate's changing framework of violence informs men's constructions of masculinity within British karate.

\section{Violent Beginnings}

Utilizing the body to develop and exert combative blows has long stood as a symbol of masculinity, and as such, a key to masculine embodiment. Such motions are not inherently male, nor are they motions that women have not engaged in historically or presently, but are uses of the body that in western society have been framed as masculine, and are commonly understood as masculine. In the karate hall, women and men engage their bodies in these combative motions, developing the techniques, awareness, and timing to be able to hold one's own in a fight. Such 
hitting techniques are essential to karate practice, and the primary way in which newcomers imagined using their body in a karate hall. For men in particular, learning how to fight was cited as a key interest in learning karate:

Fighting is what you think of when you think of karate, so that was part of the appeal learning how to fight. Not in a savage way, but just to see if I could... Scott, Lothian Wado-kai.

I loved Jackie Chan and all the fighting kids shows when I was young. I also wouldn't stop fighting with my brother, and my parents just had enough of it and thought 'we need to get this child to some kind of fighting sport!' They thought taking me to karate would mean I wouldn't fight with my brother. Then the next week he started - so it didn't really stop it. The fighting in the house changed I guess... We set up rules like 'no face hitting, only body' so we organized the fights more haha. I guess it was better - a bit less, like, actually angry - but not exactly what my parents intended.

Sean, Lothian Wadokai

For many men, starting karate provided an exciting opportunity to test themselves against an ideal of how men 'should' be able to use their bodies. The quote from Sean provides a revealing undertone embedded within many of the male interviewees' discussions of starting karate, particularly those who started at a young age - that a boy's desire to engage in fighting is 'natural' and therefore karate could provide a safe and legitimate space to release and rehearse this innate desire, rather than attempting to steer boys to non-violent activities. As such, karate's 
mimetically violent practice was positioned as a pathway for honing in an assumed natural masculine capacity. Karate's mimetically violent form was thus seen to hold masculinityvalidating potential that appeared to infuse many men's desires to start the sport.

Men's desire to learn combative movements were also often seen as beneficial, or in some cases essential, for their work life. Many of the men whom trained across the three clubs worked within occupations that frequently deal with physical aggression such as the police, door staff to pubs and clubs, and young offenders' institutions. Men were much more likely than their female training partners to be employed in such work, reflecting on going reputations of physical work as 'masculine'. For these men, the desire to start karate was explicitly linked to improving their capacities at work:

Part of my job as a teacher (at a pupil referral unit) is to avoid fights and deal with violent situations. So starting karate appealed to me because I thought 'how will I find having hits flying toward my head?' And that took a bit of getting used to, to be honest. So going into it I was kinda like 'let's see how this goes' but also thinking 'this might actually be really helpful'.

David, Juniper karate club.

As such, karate was seen as a vehicle for men to both defend themselves against the potential of violence of male work, and providing the tools to take control within such situations. Here, combative capacity is presented as a practical necessity for countering violence, alongside presenting a dichotomy of 'good violence' of their occupation, and 'bad violence' that they must protect against. In turn, such narratives further reflect desires for physical dominance that are at 
the heart of notions of orthodox masculinity. These narratives do so by at once both distancing themselves from 'real' or 'bad' violence, and associating themselves with the combative skills of karate that are presented as acceptable and legitimate.

A distancing of the apparent violence within karate from 'real' violence was a notion reiterated by all my interviewees. Those who had decades of experience within karate done so by suggesting the line between real violence and the practice of karate had not always been so clear. The 1980s were presented as a particularly physical stage in British karate's history:

In the ' 80 s it was about hitting things as hard as you could. So if you were doing pad work it would be - put your hand through the pad. If you were fighting it would be knock their head off. It was a lot more brutal. So when I came back to Colin's class twenty years later I kept getting a row for lack of control. Now it's about knowing you could hit them hard if you wanted to, but having that control and discipline... It's more about etiquette, or speed. It's about being an athlete rather than just knocking someone's head off.

Keith, Juniper karate club.

The aggressive physicality of karate in the 1980s was linked by some participants as a direct tactic to exclude women, and in turn, reinforce karate as a male domain, and karate's violence as a masculine capacity:

Back then it was seen that things like punching walls will make you stronger, and that was kind of accepted. If you were going to punch someone you were going out to drop 
them and make sure they didn't get back up. When I first started it was very much an adult thing, but it was also very much a male thing as well... It was like 'if they (women and children) can't handle what the men do they shouldn't be here'. It was an issue of: make it as hard as you can, and if people don't come back, well, they're the weak ones. Craig, Bushido.

The depictions of British karate in the 1980s above present it is an arena that exudes the values and performances of an orthodox masculinity: to be aggressive, strong, take risks, assert dominance and control, and both hostile and oppositional to women and children. The apparent 'brutality' of karate within the 1980s can be situated within broader societal trends whereby the structures of male dominance had been shaken by women's increased participation in work and public life (Whitson, 1990). Within this context, performances of orthodox masculinity were amplified as resistance to changing gender relations. Within this era, the informal feeling rules guiding karate's practices were suggested to center on expressing fearless aggression and avoiding at all costs expressing pain, whilst omitting rules concerning controlling techniques. In comparing British karate in the 1980s to present day, karate practitioners told a story of karate undergoing a civilizing process. Seen as key to this process was changes to the competitive rules of karate:

The most notable difference is the protection - we weren't given protection in those days. You turned up with a pair of cloth mitts literally that was like putting a glove on. Just cotton, and that was it. There was no shin or feet protectors or anything like that. Most of the referees were ex-fighters, so back in the ' 80 s if you hit someone hard you might be 
told 'tone it down a bit' but that was it - then you'd just leather back into them. Its a different sport completely now. And it's quite right the protection is there... What we were doing back in those days was brutalizing the sport. You were going out to get hurt or [be] hurt. If you were going to punch someone you were going out to drop them and make sure they didn't get back up. Nowadays there's a more technical aspect to it, its more a visual sport now... It used to be brutal, but now it's an art.

Stuart, Juniper karate club.

The combination of increased protective equipment, and stricter refereeing of techniques that were deemed to be exceedingly damaging, debunked the value and prestige associated with being able to hit hard. In this process physical aggression expressing violence became less central to karate's practice. In doing so, a crux of orthodox masculinity was delegitimized within British karate. However, whilst all of my participants accounts of British karate's 'brutal' past allude to karate's changes as being progressive and improving karate's practice, they also appeared to draw a joy and prestige from emphasizing the physicality of training that they had endured in the 1980s. Stories of British karate's 'brutal past' thus both worked to distance and connect the men telling the tales to an orthodox masculinity, and in doing so, enabled them to paradoxically double-up capital from both an association with an orthodox masculinity, and a civilizing masculinity that denotes the former.

\section{Embodying the art of the sport}


Changes to competition rules appeared to ignite a broader 'civilizing process' within British karate that seeped through both competition and club practice. In this, growing emphasis was placed on the 'art' of karate:

Anybody can hit someone hard. There's no real achievement in that. That's not what we're here to do. Karate is about precision, technique, always improving, and that takes quite a lot of patience. That's what makes karate impressive. Its an art, it's a life-long journey if you want it to be, and yes, you do get to hit people too, but it's much more than just hitting people.

Field note quote from Coach Craig, Bushido.

I came to understand the 'art' of the sport to refer to grace in movement, elegance in technique, control, and subtle and soft manipulations of the body - traits that fall under conventional notions of femininity. Coaches and high grades emphasized the importance of the 'artistic' elements of the sport within classes by emphasizing the importance of technical precision, control, elegance, agility, and improvement when instructing, by praising and parading those who displayed such qualities, and verbally condoning karate practice that was deemed not to be attempting to embody these qualities. Instead, karate practice was expected to involve a delicate weaving together of the body as a whole fluidly moving into technical positions, agile shifts of body weight from one leg to the other, the use of sound and rhythm to help the coordination of the body, graceful control of flexible kicks, subtle twists to change the trajectory of technique, and spatial awareness of the distance between self and imagined or real opponents. For many men, the artistic elements of karate were embraced as something to value about karate: 
To be able to lift the knee and wrap a kick so effortlessly around a target with the control to just dink a touch with the toe, and then bring it back down - magic. Particularly at my size, it feels great to be able to do that.

Keith, Juniper karate club.

The way we dance around an opponent, set up a technique, execute it to technical precision, and swiftly move away again. It's an art, that's why it's a martial art. Karate used to be about hitting people as hard as you could, there was no skill in it - it was physical and it was hard, but there wasn't much skill. Whereas now - wow. The sport's moved on and it's for the better.

Stuart, Juniper karate club.

In reflecting on karate practice as an 'art', male practitioners acknowledged the delicate and elegant intricacies of their practice that situate karate at odds with notions of an orthodox masculinity. It also marked a distinct realignment of prestige within karate from physically painful enactments of aggression, towards aesthetic and controlled performances. Within this, spatial awareness and rhythm with movement, much like a dancer, was drawn upon to glide through the patterns of kata, or execute the correct timing and movement of advances forward:

The dancing and the karate... looking back the similarities between the two of them are uncanny. Rhythm, speed, posture - all the things you need to be a good karate player. Dancing gave me all I needed. All karate added in was the technique and power, or the 
looseness of fighting competition style, but everything else - the similarities between karate and dancing are great.

Stuart, Juniper karate club.

Unlike the refrain shown from many men and boys to activities such as dance (Gard, 2008), the elegant, controlled, rhythmic motions of karate were enjoyed as part of a variety of ways of using one's body in the karate hall, supported by the masculine safety net that these movements could be utilized for combative purposes. The mixture of conventionally feminine and masculine uses of the body thus offered men a way to accept the practice within the realms of being gender appropriate.

Alongside the enjoyment many men felt performing the artistic elements of karate, an active avoidance of hurting others also accompanied this, and further complicated the position of violence within constructions of masculinity in karate. Use of 'control' when throwing techniques was felt to be a pivotal component in learning how to hit in karate, and was a key informal rule of karate practice. Hitting hard and being hit hard, although it did happen, was not felt to be crucial, nor desirable, in karate training:

When we're sparring or doing techniques I don't actually want to hurt the person I'm with. Karate's not about who can hit the hardest, it's about scoring techniques, so I don't want to hurt them.

Sean, Lothian Wado-kai. 
I punched one of the orange belts (beginners) at training the other week, and it was one of those situations where I'd aimed at his distance, started to throw it, then he moved in closer and I couldn't stop the punch. It was a sore one, right on the jaw - I felt terrible! You could see in his face he was quite taken-a-back but kept saying 'oh its fine'. I felt terrible all class! I should be better (at controlling) than that.

David, Juniper karate club.

Karate's emphasis on clean, clear, controlled, and efficient technical execution of moves meant that most hits never left training partners in any serious pain. Controlling the strength of attacks, and the degree of contact to their training partner's skin, was enjoyed with a sense of relief, particularly for lower grades whose technical ability was less finely tuned than more senior grades. Wary of their relative lack of skill, often lower grades were found trying not to accidentally hit people too hard, and would use tactics such as aiming to the body to avoid problematically hitting someone too hard. In this process, not only were uses of violence as physical violation deemed undesirable and avoided by many male karate practitioners, but in doing so, physical violation was distanced from men's constructions and performances of masculinity. Instead, the ability to throw combative techniques that could hit a training partner without hurting them was experienced with a sense of achievement and pride:

Sometimes you get into situations where your sparring and the person you're with... you start to feel they are getting frustrated and are actually trying to hurt you rather than score points. It's in those moments that if you can just lift the leg up and 'dink' tap them on the head with a beautiful kick - it feels great. It's like, 'I could have knocked you out, but I 
controlled it at the last second'. It's much, much, much harder to control a kick that knock someone out with it. It's a good feeling. Keith, Juniper karate club.

Being able to do so not only marked an achievement in performing karate techniques with success, but further built karate practitioners sense of control over their body, and, within sparring, the dominating of others. The prestige found in having 'the ability to knock them out, but controlling it at the last second' lay in contrast to the embodied experiences older members mentioned from British karate's more 'brutal' past whereby the prestige of violence as physical violation shifted towards a prestige in controlled, aesthetic, domination. The reduction of the importance of strength opened up room for women to be seen as the best practitioners, and in turn, drawing into question the exclusivity of fighting to masculinity.

For some men, the emphasis on control and elegance was unexpected when starting karate, and disregarded in favor of focusing on hitting things hard. In my field notes I reflect upon this:

Coach Angus moved us onto multiple pad-work drills. This required the class to stand in lines grouped together by height, with one person holding a body-sized pad against their body whilst one-by-one, the rest of the line took their turn to execute a number of kicks and punches against the pad. I looked over to 'the giants' line where Jason was holding the pad. John took to the front of the line, set up his stance, and fired his back leg into the pad and into Jason's body. Jason's face winced, but before there was time to get his breathe back, John slammed his foot into the pad again and again and again. His eyes were fixated on the pad, with each kick holding worse technique. Paul attempted to 
intervene 'Simmer down John, remember your technique'. John continued ignoring Paul. Paul tried again with a joke - 'Jason won't be able to walk home if you keep going like that!' John turned and smiled towards Paul, before finishing his last, technical terrible but powerful, kick.

Some men, like John, left the sport quite quickly rather than developing elegance, control, and the delicate touch essential to practicing and improving their karate. This suggests an inability to manage their masculinity within a context that required a shift away from a dominating and aggressive form of masculinity toward a blend of both conventionally masculine and conventionally feminine traits. Others found ways to re-evaluate and manage them. This entailed compartmentalizing karate into sections they liked and disliked, or reframing bodily movements that could be interpreted as feminine, as masculine:

When people think of karate they don't really think of kata (a sequence of karate moves performed solo and assessed against the perfection of execution of techniques). It's fine, but it's not for me. I'm here 'cause I enjoy sparring and things like that. Scott Lothian Wado-kai.

I think people don't realize the practical uses of kata - like what each move is doing, how that is disarming or eliminating your opponent. Like Jion is a really powerful kata I think, it's all moves that you can really put your strength into. James, Juniper karate club. 
Such interpretations positioned mimetic violence and dominance at the center of their karate practice, retaining a privilege for concepts associated with orthodox masculinity, whilst at the same time subordinating, although adhering to, aspects associated with conventional ideas of femininity. This in turn enabled some men to perform and embody the artistic movements of karate in a way that they felt maintained a sense of masculinity, whilst simultaneously performing qualities associated with conventional notions of femininity.

\section{Policing and punishing violence}

The informal feeling rules framing uses of violence within karate together set out almost paradoxical ideas about violence: as both something to avoid, as something to embody, and as something which, when experienced, karate practitioners should not complain about. Karate practitioners must walk a line fine in order to adhere to the codes of violence whereby failure to emotion manage appropriately left them susceptible to policing and punishing from high grades and the club instructor.

The experience of being hit entailed both physical sensations and marks left on the body such as bruises, cuts, and grazes, that formed a foundation for the embodied experience of karate. Newcomers and low grades were visibly much more cautious about being hit, despite taking place under rules and within a safe place. Often low grades would screw their faces after being hit with light skin touch, stay far away from their partner to avoid getting hit, move back not to allow their partner to make contact when being a target, or, in a few cases, complain to the coach of being hit too hard. Newcomers had to be persuaded that getting hit was not as painful or 
damaging as they imagined it to be, and often this persuasion developed through being hit either in sparring, when holding a pad for a partner, or standing as a target:

You take a hit to the stomach and you stop for a minute and go 'Ooh! Okay, okay, I'm still here', you know, you realize you can take it.

David, Juniper karate club.

Through taking a hit low-grade karate practitioners came to realize both that their bodies were capable of taking a hit, and that the hits themselves often did not feel as painful as the thought of them was. Through on-going hits, karate practitioners built an embodied understanding that transformed the sensation of being hit from something painful, scary, and damaging, to something normal, within their body's capabilities to deal with, and enjoyable. Coaches would encourage this interpretation of being hit by responding to moments when practitioners looked uncertain at the blow they had just taken:

We're not scared of contract, because (coach) Colin encourages it: 'nothing wrong with a wee bit of contact'...As long as you're not going out of your way to hurt some one. Keith, Juniper karate club.

Some of the clubs at competition, the kids have been punched in the face and they are having a cry and you see a coach shouting at them to get back up. James, Juniper karate club. 
Through such actions, coaches and high-level karate practitioners asserted a stoic feeling rule often used to police performances of masculinity: that being hit was okay, but expressing pain, unless under exceptional circumstances, was not. Whilst there was an understanding that lower grades may be unfamiliar with getting hit, as being hit was seen as 'part of the sport' experienced karate practitioners' disgruntlement at being hit or exaggeration of injury was frowned upon by the coach and other practitioners. However, there were visible and tacit disparities in the extent to which male and female karate practitioners were held to this rule. I reflected upon this in my field notes:

I had partnered with Lisa who, despite being a black belt, tended to stick with other adults who also started karate in their 30s or 40s. We were to start with body punches then moved onto head kicks - ten each to warm up. The first kick I threw made a perfect slap against her cheek, and although it did make contact, it was only a little tap - in competition I would be delighted with it, it was the perfect level of contact. I could see instantly in her face that she was completely shocked; her previous smile had dropped to a look of concern before quickly trying to fake a smile again. The reaction shocked me, because the kick really wasn't hard, however to Lisa it was, because it mustn't have been the degree of contact she had been used to. I attempted to watch how she sparred with others during the class, and noted that those who trained with her appeared to avoid making contact with her, which was very strange treatment for a black belt. I had seen Colin once react in the same way when sparring with Sean before he received his black belt, and coach Eric joked 'if you can't take that by now you're in the wrong sport'. Field notes, Lothian Wado-kai. 
In situations where high grades show distain to being hit, as described above with Lisa, negative reactions to being hit with appropriate contact often resulted in: hitting the partner again with the same intensity; a senior grade telling the partner they must learn to take a hit; in some cases, hitting the partner harder; and in rare cases, the individual having to fight numerous people one after another, in an attempt to cement the idea that in karate, you will get hit, and you can take it. Whilst high-grade women were sometimes excused for showing distain towards being hit, particularly if they were partnered with a man, high-grade men were held tightly to taking a hit by the punishing mechanism mentioned above. Such treatment molded men and women's embodied experiences of karate differently. Women had leeway to express pain and be excused of punishment based on underlying assumptions of women's bodies as less suitable or capable than men's to take a hit. Receiving painful hits and hiding emotional distain was in turn made fundamental to high-grade men's embodied experience of the sport, in turn reinforcing ideas of men as 'natural' fighters and their innate capacity for fighting being central to their distinction from women.

A crucial part in accepting being hit was interpreting the kicks and punches being thrown as without an intention to do harm and without being vindictive:

Within that 30 second window, whatever happens, happens. When it comes to training you can't hold a grudge. I've had burst lips, black eyes, bloody nose... Getting hit is just normal now, you get used to it. I don't think 'I'm going to get you for that'. What I have thought is 'you silly bugger Sean, you should have gotten out the way...'. And the minute you are told to stop, you have to stop. You have to leave it on the mat because if 
you didn't you couldn't train. Every time you'd turn up to training, you'd be thinking

'I'm going to hurt that person' and you can't do that. Most of the time if someone hurts you they are apologetic about it!

Sean, Lothian Wado-kai.

As part of a mutual exchange of thumps, bumps, and bruises in an attempting to get better at a shared passion, pain caused by one partner to another was overlooked. Accepting being hit, and appreciating it as part of learning rather than a challenge over one's dominance or ability, was seen as important both in being able to improve in the sport, and in being able to emotionally come to terms with being hit and respond in an appropriate manner. In the quote above, Sean outlines a narrative of avoiding 'natural' emotional, violent, reactions to being hit, with reasoning, learning, and improving. This replicates a civilizing narrative in that Sean aligns himself with civility and control, and distances himself from emotive violent reactions.

Continually hitting a training partner hard in order to hurt them was seen as both unnecessary, unfair, and unproductive for karate training. Regular culprits of this were well known within the karate clubs, and were often avoided. High grades would often police such behavior by partnering the culprit and unleashing hard, fast, and rough techniques in an intense fight to punish the deviant practitioner, show them they were not the only person who could hit hard, and encourage them to thus adhere to the rules of control. This policing worked to reinforce the norms of hitting, and punishment acted to assert authority over other's embodied actions. Such treatment could be seen within low-level club fighting to the very top level of karate training: 
Nobody should be getting black eyes or bleeding noses in here. It'll be physically intense, and it'll be scary, but nobody should be getting hurt. If you're here to hurt people, well, you're in the right place - the national coaches here have no problem in bringing you out to fight with us.

Scotland coach, national squad training.

Here, the behavior being punished is the same behavior that will be used to punish. Whilst all high grades have the skill to hit and hurt an opponent, not all had the physical build to out-punch karate practitioners who kept hitting others hard. Most commonly this deviant behavior was performed by men, and was punished by another man. Such confrontations raised contentions not of whether it is okay to hit hard, but of who has the authority to hit hard within what context. Men's focus on their ability to do physical damage transformed the controlled, hierarchically-skill-structured, 'art' of karate into a contestation to be the hegemonic male (Connell, 2009), enabled and moralized by claims of being for the greater good. The reinforcement of the rules of control to macho types was particularly carried out when a man was deemed to be purposefully hitting a woman training partner too hard:

Big Freddy was always throwing these massive big kicks, punches, and hooks, and nobody wanted to fight him because of it. I just thought 'that's not karate, that's just shocking'. One time he gave Arlene a burst lip it tipped me over. I mentioned it to coach Colin and he said 'someone will put him in his place' sort of giving me the nod. So I paired up with Fred, we bowed and he through a hook at me - I stepped back. He through a round house kick at me, and luckily, I ducked as his leg swung right through like a 
pirouette. When he came back round, I threw probably one of my best technical face punches I've ever thrown, and I caught him right under the nose and he fell back. He threw his pads off and got straight back up shouting 'I'll fucking show you' so then I started to take my hand pads off, and Colin just sort of walked over as if to say 'put your pads back on boys and simmer down. This is karate.' After that in the car park Fred was shouting over and I said 'Fred if you want to, go for it, but if you do one of us aren't coming back to training'. I just thought - he's a bully, nothing but a bully. Hitting people I don't take great pride in, but with him... the first thing I said to my wife was that I punched Fred off his feet, and she said 'did he deserve it?' and I said 'aye he did' then she said 'well he had it coming then'. So I was kind of gloating but also trying to process it in my own mind - was that right what I did? But aye, that I did take pride in. Keith, Juniper karate club.

As such, whilst an orthodox masculine embodiment centered on exerting physical strength upon the bodies of others to gain prestige was discouraged within karate classes, an association between men's bodies, violence, control, and authority was maintained. Here, black belt men became the physical guardians of social order within the club, whilst women were predominantly isolated from this role because of their body size, and thus reserving an ultimate authoritative embodiment for men. Here, the protection of women's bodies was placed as central to performing a masculine embodiment, and utilized to legitimize purposively physical and aggressive attacks upon other men.

\section{Conclusion}


As a practice based on mimetic performances of violence, karate, at first glance, would appear to be a prime arena for reproducing orthodox masculinity, and awarding such orthodox performances of masculinity with hegemonic prestige. However, the shift in prestige from being able to hit hard to being able to control techniques marks a shift not only in karate's direction as a sport, but also in karate's relationship with ideas of orthodox masculinity. Whilst notions of hitting hard tie in well with legitimizing ideas of orthodox masculinity, and indeed framed British karate's practice in the past, karate practitioners were no longer expected nor desired to hit their training partners as hard as they could, but instead hit with control, speed, technical accuracy, and respect for their training partner or opponent. Being able to hit hardest no longer appeared to warrant prestige, nor fast track the largest men in the club to top positions of the hierarchy, but rather was seen as poor karate etiquette and thus discouraged. Redirecting prestige from being able to hit hard, to being able to control darting and agile technically excellent kicks and punches not only rejected notions of orthodox masculinity, but also opened up interpretations of the best fighters to be women as well as men. In turn, this drew into question the exclusivity of fighting to men's bodies, and in doing so, also posed the question: what is masculine about fighting?

As women's combative uses of their bodies presented such movements as embodiments expected, and capable, of men and women, more nuanced ways of associating men with the dominance drawn from fighting skills and violence emerged. This included being held more tightly accountable to the informal feeling rules surrounding karate practice, in particular, withholding expressions of pain, controlling the physical contact of techniques thrown, and maintaining a determined, fearless, and aggressive facial and bodily demeanor. The extensive policing and physical punishing of men whom slacked on these fronts, in comparison to the 
treatment of their female training partners, reinforced the importance of stoicism and violent capacity to masculinity. The frequency with which men were punished by other men for being deemed to hit women with excessive contact placed the protection of women as central to performances of masculinity within a civilizing British karate class. By marking women as comparatively fragile, and ultimately in need of assistance from men, this further reinforced notions of violent capacities as distinctly central to masculinity.

The embodiments of those whom punished violence within the karate classes paradoxically both denounced uses of excessive physicality and valorized excessive physicality. Within these interactions, the punishers took on a hegemonic position within the club that, through the caveat of moral reason and righteousness rather than emotive outburst, legitimized their uses of violence and maintained the link between masculinity, violence, and dominance. Those who had practiced karate in the 1980s similarly drew on an association with karate's 'brutal' past to access a form of masculine capital associated with violence. As such, in drawing on narratives of civilizing morality and restraint of emotionality, men within contemporary British karate were able to build gender performances that drew masculine prestige from both disassociated themselves from an orthodox masculinity by virtue of embracing acts more commonly associated with femininity, and simultaneously performing stoic, mimetic, performances of violence. 


\section{References}

Allen-Collinson, J. (2009). Sporting embodiment: sports studies and the (continuing) promise of phenomenology. Qualitative research in sport and exercise, 1(3), 279-296.

Anderson, E. (2005). Orthodox and inclusive masculinity: Competing masculinities among heterosexual men in a feminized terrain. Sociological perspectives, 48(3), 337-355.

Anderson, E. (2008). 'I used to think women were weak': Orthodox masculinity, gender segregation, and sport. Sociological Forum, 23(2), 257-280.

Anderson, E. (2009). Inclusive masculinity: The changing nature of masculinities. Routledge.

Bourdieu, P. (2001). Masculine Domination. Cambridge: Polity Press.

Channon, A. (2013). Enter the discourse: exploring the discursive roots of inclusivity in mixedsex martial arts. Sport in Society: Cultures, commerce, media, politics, 16(10), 12931308.

Channon, A. \& Matthews, C. (2015) Approaching the gendered phenomenon of "women warriors'. In Channon, A. \& Matthews, C. (eds.) Global perspectives on women in combat sports: Women warriors around the world (pp1-21). Basingstoke: Palgrave Macmillan.

Connell, R.W. (1990). An Iron Man: The Body and Some Contradictions of Hegemonic Masculinity. In Messner MA and Sabo DF (eds.) Sport, Men and the Gender Order: Critical Feminist Perspectives. Champaign Illinois: Human Kinetics, 83-96.

Connell, R. W. (2005). Masculinities. California: University of California Press

Dunning, E. (1999). Sport Matters: Sociological studies of sport, violence, and civilization. London: Routledge. 
Elias, N. \& Dunning, E. (1986). Quest for Excitement: Sport and leisure in the civilizing process. Oxford: Blackwell.

Garcia, R.S. \& Malcolm, D. (2010). Decivilizing, civilizing, or informalizing? The international development of Mixed Martial Arts. International Review for the Sociology of Sports, 45(1), 39-58.

Hargreaves, J. (1994). Sporting Females: Critical issues in the history and sociology of women's sports. London: Routledge.

Hatty, S.E. (2000). Masculinities, Violence, and Culture. London: Sage.

Hochschild, A. (1983). The managed heart: The commercialization of human feeling. Berkley: The University of California Press.

Kidd, B. (2013). Sports and masculinity. Sport in Society, 16(4), 553-564.

Kimmel, M.S. (2000). The Gendered Society. Oxford: Oxford University Press.

Klein, A.M. (1993). Little big men: Bodybuilding subculture and gender construction. New York: State University of New York Press.

Laurendeau, J. (2014). 'Just tape it up for me, ok?': Masculinites, injury and embodied emotion. Emotion, Space and Society, 12, 11-17.

MacLean, C. (2015). Beautifully violent: The gender dynamic of Scottish karate. In Channon, A. \& Matthews, C. (eds.) Global perspectives on women in combat sports: Women warriors around the world (pp155-171). London: Palgrave Macmillan.

MacLean, C. (2016). Friendships worth fighting for: bonds between women and men karate practitioners as sites for deconstructing gender inequality. Sport in Society, 19(8-9), 1374-1384. 
Matthews, C. \& Channon, A. (2017). Understanding Sports Violence: Revisiting Foundational Explorations. Sport in Society, 20(7), 751-767.

McDonagh, E. \& Pappano, L. (2008). Playing with the boys: Why separate is not equal in sports. New York: Oxford University Press.

McNaughton, M.J. (2012). Insurrectionary Womanliness: Gender and the (Boxing) Ring. The Qualitative Report, 17(33), 1-13.

Meo, A. (2010). Picturing students' habitus: The advantages and limitations of photo-elicitation interviewing in a qualitative study in the city of Buenos Aires. International Journal of Qualitative Methods 9(2): 149-171.

Messner, M.A. (1990). When bodies are weapons: Masculinity and violence in sport. International review for the sociology of sport 25: 203-220.

Noel, H. (2009). Un-doing gendered power relations through martial arts?. International Journal of Social Inquiry 2(2): 17-37.

Padfield, M \& Procter, I. (1996). The effect of interviewer's gender on the interviewing process: A comparative enquiry. Sociology, 30(2), 355-366.

Pini, B. (2005). Interviewing men: Gender and the collection and interpretation of qualitative data. Journal of Sociology, 41(2), 201-216.

Pink, S. (2009). Doing sensory ethnography. London: Sage.

Pringle, R. (2009). Defamiliarizing Heavy-Contact Sports: A Critical Examination of Rugby, Discipline, and Pleasure. Sociology of Sport Journal, 29, 211-234.

Raven, S. \& Hansen, H.P. (2013). How to explore dancers' sense experiences? A study of how multi-sited fieldwork and phenomenology can be combined. Qualitative research in sport, exercise and health, 5(2), 196-213. 
Schacht, S. (1996). Misogyny on and off the 'pitch': The gendered world of male rugby players. Gender and Society, 10(5), 550-565.

Smith, R. T. (2014). Fighting for Recognition: Identity, Masculinity, and the Act of Violence in Professional Wrestling. Duke University Press.

Spencer, D.C. (2012). Narratives of despair and loss: Pain, injury and masculinity in sport. Qualitative Research in Sport, Exercise and Health, 4(1), 117-137.

Spencer, D.C. (2014). Sensing violence: An ethnography of mixed martial arts. Ethnography, $15(2), 232-254$.

Wacquant, L. (2004). Body \& Soul: Notebooks of an apprentice boxer. Oxford: Oxford University Press.

Wang, C. (1999). Photovoice: A participatory Action Research Strategy Applied to Women's health. Journal of women's health, 8(2), 185-192.

Wellard, I. (2001). Men, sport, body performance and the maintenance of 'exclusive masculinity'. Leisure Studies, 21(3), 235-247.

Whitson, D. (1990). Sport in the social construction of masculinity. In Messner, M.A. \& Sabo, D.F. (eds.) Sport, Men and the Gender Order: Critical Feminist Perspectives (pp19-31). Illinois: Human Kinetics.

Woodward, K. (2007). Boxing, Masculinity, and Identity: The 'I' of the Tiger London: Routledge.

Young, K. (2012). Sport, Violence and Society. London: Routledge. 